\title{
Fitting Teacher Education in/to/for an Increasingly Complex World
}

\author{
BRENT DAVIS \& DENNIS SUMARA \\ University of Calgary (Canada)
}

\begin{abstract}
Oriented by complexity thinking and informed by a selection of "game-changing" research findings in the educational literature, we describe a set of innovations to a teacher education program. These innovations include broad awareness of theories of learning, specialization across levels, integration of pre-service and in-service offerings, a developmental curriculum, and deep partnerships with schools.
\end{abstract}

Systems/complexity thinking has come of age. A few decades ago, it was still being described as the "new paradigm" and an "emerging worldview." Now virtually all research in the physical sciences is implicitly complexivist - and one would be hard pressed to find research in the social sciences and humanities that is not deeply committed to such notions as co-participations, complex entanglements, decentralized structures, co-adaptive dynamics, self-determination, and non-linear unfoldings.

This point is certainly true of the field of educational research. As we have detailed elsewhere (Davis \& Sumara, 2006; Davis, Sumara, \& Luce-Kapler, 2008), one might summarize complexity-oriented research in terms of three distinct phases. For convenience, we'll label these phases as Complexity 1.0, 2.0, and 3.0, and we argue that the Complexity 3.0 is well aligned with the purposes and needs of the project of formal education. After that, we will look at a selection of "game-changers" that are drawn from research both inside to and outside the field of education. Finally, we will look at the project of teacher education - specifically, our own program at the University of Calgary - to offer one example of how the insights from this burgeoning field of inquiry might inform and transform educational projects.

\section{A brief history}

The first major development in the emergence of complexity research was, of course, the recognition that there is a class of phenomena that cannot be understood in terms of simple cause-effect dynamics. In the western world, that recognition was formally announced in the 1800s through the work of Charles Darwin and his contemporaries, but it took more than a century for the sensibility to percolate to and through other branches of science.

Indeed, it wasn't until the late 1970s that the shift in mindset was recognized and named. It took until then for a necessary critical mass of like-minded researchers across 
the sciences to arise and to collect insights into the self-similar dynamics of ant colonies, brains, cities, cells, and so on under the banner of "complexity theory." We call this phase "Complexity 1.0," and it was focused mainly on description. The major accomplishment was a cross-disciplinary recognition of a class of non-reducible (emergent) phenomena that would not surrender their secrets to the tools of classical, analytic science. Infusing this movement was a new set of images and metaphors to describe these diverse phenomena. Figures based in Euclidean geometry and actions rooted in Newtonian physics were gradually replaced by images drawn from fractal geometry (e.g., scale independence, surprising detail) and the structural dynamics of biology (e.g., ecosystemic organizations, dynamic interdependencies). A principal visual metaphor at the time was that of nested systems (see fig. 1a), reflecting the important insights that systems were both irreducible (i.e., they must be studied at the levels of their emergence) and comprising similarly complex systems.
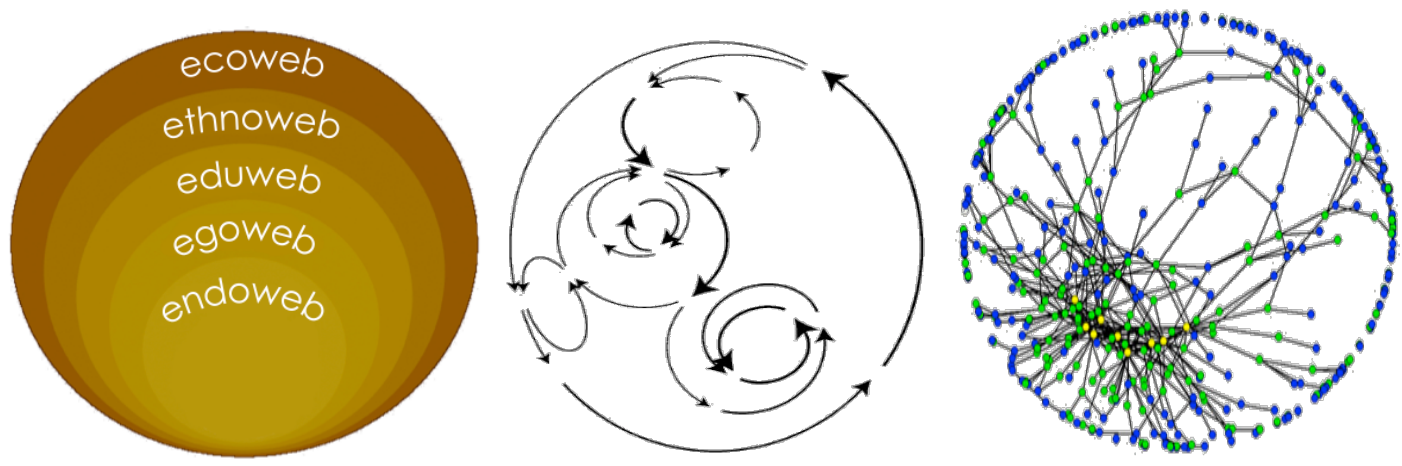

Figure 1. Three important visual metaphors within complexity research corresponding to the major emphases within three phases of the movement - (a) nested systems, (b) entangled dynamics, and (c) decentralized networks.

As more and more phenomena were recognized as complexly emergent and more and more fields of inquiry came to be involved in the project of complexity research, the focus of inquiry was elaborated beyond description of complex dynamics into analysis of the similar roots, structures, and consequences of these dynamics. This "Complexity 2.0" phase roughly spanned 1980 through 2000, and it was characterized by increasing use of such notions of recursive processes within cycles of development and growth (see fig. $2 b$ for one of the principal visual metaphors of the time), with the notion of "living systems" prevailing in comparisons of complex and not-complex entities. It was a time of explosive growth in complexity research. Indeed, as evidenced by the recipients of Nobel Prizes in physics, medicine, chemistry, and economics, it was the coming of age of complexity. The winners in 1980 might be retroactively interpreted in terms of complexity theory, but they were not explicitly aligned with the movement. The winners in 2000 were clearly complexivist.

Since 2000 or so, complexity research has become decidedly more pragmatic in its emphases. Elaborating its ongoing interests in description and analysis, a strongly articulated component of the current work is on occasioning the emergence of complex phenomena - that is, not just identifying them, not just better understanding what makes them go, but more deliberate efforts to trigger them into being, to support their development, and to sustain their existence. As might be expected, the foci of discussions are shifted to reflect this concern with pragmatics, and is now largely organized around matters of scale free connective networks (see fig. 1c) and the way that these networks enable learning systems. 
With this shift toward pragmatics and the combined notions of nested, coentangled, and networked learning systems, we feel that complexity/systems thinking has reached a place where it can be of great use to educators - who are, after all, simultaneously concerned with multiple levels of organization (e.g., individual learners, classrooms, schools, school districts, society), co-specifying dynamics (e.g., between teachers and learners, between knowledge and action) and complex associations (e.g., among people, among ideas). Moreover, education is an explicitly pragmatic enterprise. It is charged with the tasks of supporting the wellness and possibility of individuals while supporting the maintenance and evolution of society. Complexity 3.0 enables this work.

\section{Five game-changers}

We now move to brief discussions of five "game-changers" for education - that is, complexity-informed developments from both inside and outside the field. We emphasize that these are only a tiny subset of the ones that might have been highlighted. The intent, then, is not to say that these are the only ones, nor to suggest that they are the most important ones. It is, rather, to indicate that research developments are changing the nature of the project of education.

\section{Game-Changer 1: Definitions of 'learning' and 'learners' are evolving rapidly.}

Reflecting the trends within Complexity 3.0, one of the most significant evolutions in the recent educational literature is around the core notion of learning. In a massive shift of attitudes, learning is now broadly acknowledged as poorly understood and immensely complex. That's a change from the belief rooted in a demandingly empiricist version of behaviorist psychology that prevailed 50 years ago and that still lingers in the forms of measurement-based outcomes and tight management regimes.

In a further shift from the situation in the mid-1900s, when educational discourse was dominated by behaviorism, today there are literally hundreds - perhaps thousands - of theories of learning at play in the educational literature. Some researchers see this proliferation of perspectives as a fracturing of the field. Indeed, much of the educational literature over the past decade has been focused on specifying the fine-grained distinctions among different frames - between, for example, radical constructivism and social constructivism, between actor-network theory and activity theory, embodied cognition and enactivism, and on. For our part, we choose to focus not on where theories fracture but on how they might complement and elaborate one another. Our principal strategy in these efforts is to compare their units of analysis. Phrased differently, we ask, "Who/ what is posited as the learner within each theory?"

In Figure 2, we attempt to illustrate how this tactic enables us to think across theories of learning (right column) and ways to study learning (left column; see Davis \& Sumara, 2006, for an extended discussion). Briefly, this nested conception, in which learning phenomena are seen to be enfolded in and to unfold from other learning phenomena, highlights which level of organization is the primary focus of each theory, how such primary foci inform and extend the discussions that address other levels, and how those of us involved in formal education must be simultaneously be interested in every level. We are, after all, doing more than seeking to affect individual psyches. We are inextricably involved in the ongoing transformations of social collectives, cultures, ecosystems, and other intersecting and overlapping learners. 


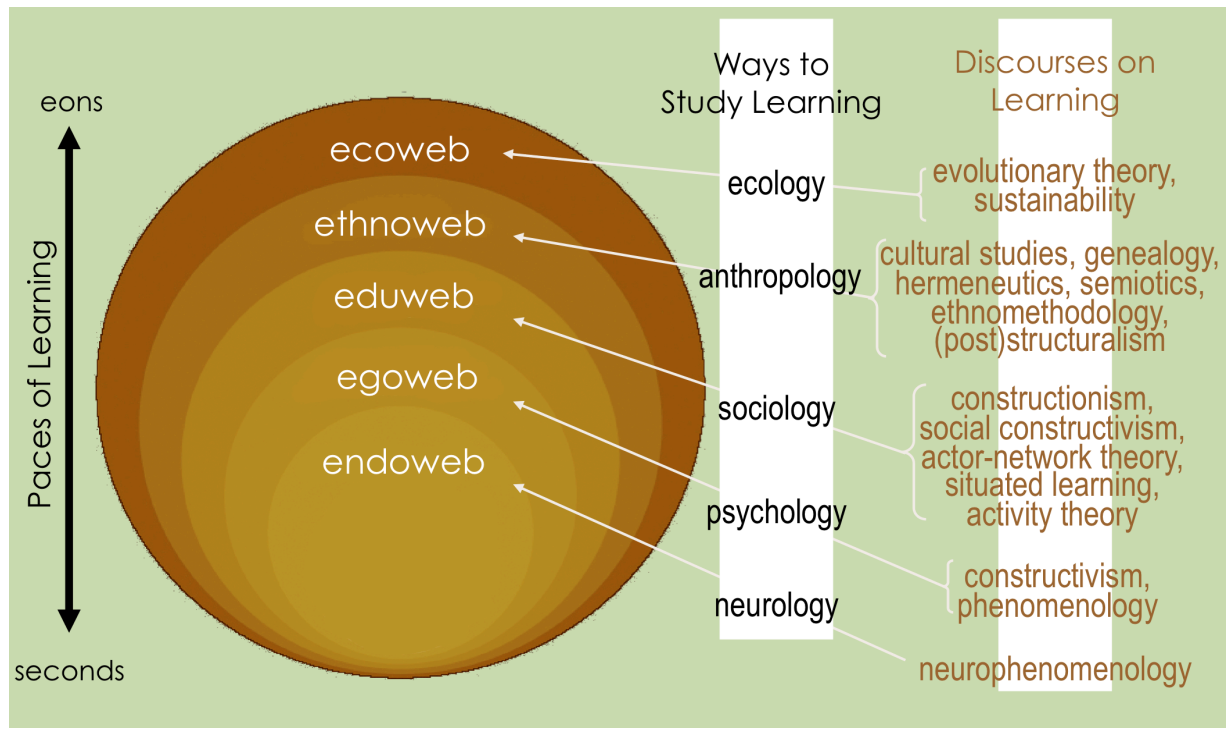

Figure 2. Some of the learners of interest to educators

\section{Game-Changer 2: Intelligence/ability is more (l)earned than bestowed.}

Intelligence and ability are not well understood, and a quick review of some of the images and metaphors that are invoked in English in discussions of the topic prove that point. Ability is commonly seen as a mystical bestowal (e.g., "She's gifted. He has little talent."), luminosity (e.g., "He's brilliant. She's a little dim."), speediness (e.g., "She's quick. He's a little slow."), acuity (e.g., "He's sharp. She's a little dull."), and a capacity (e.g., "She's got lots of smarts. He's lacks potential."). The range and variance of images and metaphors suggest a phenomenon that eludes deep understanding.

That lack of understanding has permitted some uncritical assumptions to prevail and persist. For instance, in everyday commonsense terms, intelligence and ability are all about pre-determined limits and fixed brains - and none of the popular images for ability (mentioned in the previous paragraph) interrupt this assumption.

In many ways, this belief has been institutionalized in modern schools - through intelligence testing, differentiated streaming, gifted classes, and so on. In the face of such structures, it can be difficult to appreciate a troubling recent assertion: there are no validated accounts whatsoever of genius erupting full-blown without years of concentrated effort. That is, intelligence and ability are neither pre-set nor given; they are learned. Several elements have been identified as vital in the emergence of 'genius,' including starting early in life, practicing intensively (i.e., hours each day), practicing extensively (i.e., over many years), taking lessons even when at ones peak, and constantly engaging in 'effortful' study. (See Colvin, 2008 for an extended list and discussion.)

The notion of effortful study is particularly important. It is the sort of practice that happens at the limits of current competence, where there is a genuine likelihood of failure. However, lack of success here is not seen as demeaning or defeating. It is informative and transformative. An obvious implication - that learners should be challenged to the limits of their abilities - is almost diametrically opposed to popular notion in the English-speaking world that teaching is mainly about facilitating (i.e., literally, making easy). On the contrary, to support the development of great ability - of which all humans, it seems, are capable - teaching must challenge, push, provoke, stretch, demand, make difficult. 


\section{Game-Changer 3: Learning/knowing is more an analogical process than a logical process.}

One of the long-standing assumptions in formal education - in place at least since the Scientific and Industrial Revolutions - is that humans are logical, rational creatures. It is a principle that is deeply rooted in western philosophy, anchored to the remarkable success of the logical enterprise of mathematics.

The implicit (and problematic) image here is that of a building. It all starts by establishing solid basics/foundations and then proceeds systematically to more complicated level through a sequence of incremental logical steps. This is the model of truth that was championed by rationalist philosophers 400 years ago, and it is the image that was adopted by educators to design and implement formal curricula. Hence the linear movement through programs of study, starting with universal sets of 'basics.' Evidence that this notion is deeply entrenched in the collective mindset can be found in the pervasive use of such mechanistic notions as the brain-as-computer metaphor - that is, a dynamic, evolving form is popularly understood as a logic-based structure that takes in, stores, processes, and outputs information. In kindest terms, the analogy couldn't be more misleading.

The issue is that humans aren't logical beings. Yes, we are all capable of logic, but that is a learned capacity that rides atop our abilities to make connections among widely and wildly disparate phenomena and experiences. Consider, for example, the many associations that are used to describe intelligence, some of which we mentioned in the first paragraph of the preceding section. In brief, humanity's main strategies for drawing inferences are actually associative rather than rational - that is, humans prefer analogic over logic and induction over deduction.

There are many, many implications for formal education here. For instance, centuries-old structures for curriculum that are founded on the model of a mathematical argument need to be interrogated. Another matter of urgent need is the investigation of teacher knowledge - and this point has not been lost on researchers. Shulman (1986) was among the first to suggest that teachers' disciplinary knowledge is not simply a matter of 'more of' or 'deeper than' what is expected of their students; rather, teachers' understandings of a subject area revolve around "the most useful forms of representation of those ideas, the most powerful analogies, illustrations, examples, explanations, and demonstrations - in a word, the ways of representing and formulating the subject that make it comprehensible to others" (p. 9, emphasis added). The call is for an flexibly associative curriculum for teachers, not a rigidly logical one.

\section{Game-Changer 4: Teachers participate in creating the type of learning (deep/surface) and learners (growth/fixed mindset) they encounter.}

Marton and Säljö (1976) made a major contribution to the educational literature when they offered a distinction between two types of learning. "Surface learning," they suggested, is extrinsically motivated, oriented to doing only the minimum needed to fulfill explicit requirements, and supportive of procedural rather than conceptual understandings. It is evident in a reduction of learning tasks to 'hoop-jumping' exercises of guessing 'what the teacher wants'. In contrast, "deep learning" is motivated by the excitement of knowing more deeply, by uncovering or creating new layers of insight, by taking tasks beyond minimal requirements into spaces of explorative possibility.

As helpful as this categorization is for distinguishing among student attitudes and 'explaining' very different modes of engagement, until very recently it wasn't particularly useful in the design of teaching emphases. That's changed with Dweck's (2007) research into different mindsets. Dweck distinguishes between people with a "fixed mindset" and those with a "growth mindset." Bringing together Marton and Säljö's distinction with emergent literatures on intelligence and talent, Dweck suggests 
that the key element that differentiates learners is their belief about ability. Fixed mindset learners believe that ability is static, and so their performances are intended to prove or validate that fixed ability through impeccable performances. Growth mindset people, in contrast, see ability as learned - and so performances and engagements are all about stretching and developing ability. Some of the differences between these mindsets are obvious in the ways that challenges and obstacles are met. Someone with a fixed mindset will see a challenge as a threat and try to avoid it, and an obstacle will trigger refusal or resignation. For a growth mindset person, a challenge is an opportunity and an obstacle triggers persistence and increased effort.

For educators, Dweck's major contribution isn't her elaboration of the distinction between surface learning (fixed mindset) and deep learning (growth mindset); it is her research into the way that teachers contribute to the types of learners we encounter. Stated nakedly, teachers play a big role in creating learners' attitudes. For example, the simple act of praising ability ("Good work, Sonya. You're brilliant!") supports fixed mindedness, whereas praising effort ("Good work, Sonya. I can see that you really worked hard at this.") contributes to growth mindedness. Other facets of teaching that contribute to the creation of learner attitudes include how new topics are framed (e.g., presenting new ideas as fixed knowledge and in terms of right/wrong, versus presenting new ideas in terms of emergent knowing and with reference to the authors, artists, and scientists who struggled to generate new insights), and how classroom tasks are designed (e.g., incrementally graduated and uniformly assigned, versus open to differentiation and inviting of effortful study). Briefly, teachers tend to act out their own mindsets.

\section{Game-Changer 5: 'Good' teachers do make a big, big difference.}

The No Child Left Behind initiative in the United States has been justly criticized for its many flaws. However, there is at least one positive element in its legacy. It has provided an immense database on teacher effectiveness. It turns out that there are some teachers who, regardless of circumstances, are much more successful than others in prompting their students toward school success - year after year (see, e.g., Rivkin, Hanushek, \& Kain, 2005).

The emerging statistics are shocking in many ways. For example, when the operational definition of 'good' teachers is given in terms of those whose students progress at least 1.5 academic years in a single school term, and 'not-so-good' teachers as those whose students progress 0.5 years or less on average, some startling facts arise. It turns out that virtually all of the students of the good teachers make above-average progress, whereas only already-successful students of not-so-good teachers manage to make even average progress. These effects are not just additive; they're multiplicative. After just 3 years, students who were fortunate enough to be with 'good' teachers are on average $50 \%$-iles ahead of their age-mates who weren't so lucky.

It's important to emphasize that it's the teacher, not the general circumstances that is the critical detail here. In fact, controlling for almost every factor that is under a school's control (class size, per-pupil funding, time per class, curriculum, classroom resources, break time, etc.), only one proves to have a large impact - the teacher the student had been assigned to.

$$
\text { And so ...? }
$$

\section{What's multiplication?}

Over the past decade we have asked this question to nearly 5000 people including students, parents, teachers, and researchers. In a testament to the uniformity 
and effectiveness of public schooling, the responses have shown a stunning regularity across populations: virtually everyone who is willing to answer is adamant that multiplication is repeated addition and/or some sort of grouping process. Full stop.

Unfortunately, this 'definition' is inadequate for topics and applications that arise as early as the middle grades. How, for example, does one add $5 / 8$ to itself $3 / 4$ times, -2 to itself -3 times, or $d$ to itself $\pi$ times? It gets even worse by high school with topics in algebra and geometry where addition- and grouping-based conceptions are not only limiting, they can actually be debilitating. They force students into not understanding.

For us, this is an issue of equity and justice. A person who does not have access to a more nuanced education on multiplication will almost certainly be compelled to use rote memorization and procedural application in order to get through more sophisticated topics. The concern isn't limited to mathematics. We might just as easily have drawn our illustration from reading, the sciences, the arts, or physical activity. The simple point is that inherited practices and assumptions - of the sort challenged by the game-changers presented in the preceding section - are principal contributors to cultural inequities and educational injustices. As such, there are sound educational responses. In this section, we speak briefly to complexity-prompted shifts in structures and emphases to teacher education that, we hope, might help to address many issues of equity and justice simply by avoiding creating them in the first place. (For elaborated discussions of each point, see Chapman et al., 2010).

\section{Innovation 1: Learning about learning}

What is a teacher an expert in? Perhaps the most commonsensical answer to this question is that teachers are experts in teaching. But this circular manner of response is troubling in the face of other professions' ready self-descriptions - physicians are experts in medicine, lawyers in jurisprudence, and so on. We offer here that teachers should be learning experts, an assertion that begins with an awareness that any deliberate effort at teaching presupposes a theory of learning - and so, prospective teachers have an obligation to be attentive to the beliefs about learning that are enacted in their practice. It is about developing a sort of theoretical connoisseurship by developing awarenesses of vital distinctions, varied implications, and hidden assumptions.

Our use of the word learning rather than the word learner is important here. There is an overwhelming and commonsensical tendency to interpret the word learner in terms of individual cognitive agents, rather than agents nested within communities of agents (Bransford, Brown, \& Cocking, 2000). The word learning, we hope, might help to avoid some of this tendency, shifting attentions to complex processors, interlacing systems, and diverse perspectives (i.e., calling up the images in fig. 1, rather than the image of the individual student).

\section{Innovation 2: Specializing}

As Gambhir et al. (2008) detail, initial teacher education programs tend to be organized around distinct emphases that separate primary/elementary from secondary levels, with the assumption being that the "knowledge required and role of teachers is slightly different depending on the grades taught thus influencing elements of initial teacher education" (p. 10).

Briefly, and with few exceptions, teachers in the elementary division are prepared as generalists, whose pedagogical knowledge is expected to include at least mathematics, English language arts, science, social studies, fine arts, and health/physical education. The opposite occurs at the secondary level, where no Canadian university offers generalist programs (Crocker \& Dibbon, 2008). Rather, teacher candidates are typically expected to develop two specializations, usually both 
curricular, but one of which might not be (e.g., special education or counseling). Where middle school programs are offered, they tend to be structured as generalist programs with some manner of emphasis in at least one subject area (ibid.).

The dearth of specialist offerings for those interested in the lower grades is readily explained in terms of the everyday realities of an elementary school. However, such an approach might be argued to be lacking on at least two counts. First, it does not incorporate a broad cultural and academic shift toward a 'new' interdisciplinarity through which teams of specialists with varied but compatible and complementary expertise collaborate. Many elementary schools are already enacting a version of this sort of interdisciplinarity (albeit mainly on an ad hoc basis, lacking access to appropriately prepared specialists). Second, programs that emphasize generalist preparation may not adequately take into account the recent emergence of robust research into the disciplinary knowledge that is necessary for effective teaching - such as Shulman's "pedagogical content knowledge." For each domain, this knowledge is vast. Expecting individuals to develop an adequate mastery across domains might border on the ridiculous.

In terms of visual metaphor, the important image here is Figure 1c, in which the power of the network is understood to arise in the contributions of each node of the network. Those nodes must, of course, have much in common in order to comprise a functioning system. However, the intelligence of the system arises in their differences, their specializations. This realization confirms the traditional educational emphasis on establishing common backgrounds while introducing a new challenge: how might educators support the development of specialized competencies?

\section{Innovation 3: Initial-and-ongoing teacher education}

At the University of Calgary, we're moving toward a model that explicitly links initial and ongoing teacher education. We acknowledge that initial teacher education experiences are only an introduction. We share with the profession of teaching the responsibility to support the ongoing learning of educators. In foregrounding the complexity of teaching, we acknowledge that learning to teach is a career-long undertaking. The Faculty's commitment to the development of excellence in teaching will also be realized in our involvements in ongoing teacher education focusing, in particular, on offering experiences to support educators in their first years of professional practice through involving them in courses that are informed by and, where possible, linked to current research projects. The aim here is to go beyond introducing prospective and practicing teachers to the results of the latest studies; we are also seeking to engage them in the ever-unfolding project of identifying and understanding the work of an educator in a rapidly changing world.

There are several complexity-based principals at work in this shift in emphasis. For example, the notion of constant learning/development is implicit in discussions of complex entities. In this frame the idea that one might prepare teachers in advance is understood as naïve and troublesome. Moreover, the very notion of 'teaching' is evolving with the needs and nature of society, and that recognition alone compels us to recast teacher education in life-long terms.

\section{Innovation 4: An integrated, developmental curriculum}

Our guess is that most teacher education programs were originally developed around coherent, comprehensive, and integrated sets of ideas. As time passed, and as responsibilities for different components fell to different individuals, units and departments, in many contexts these curricula became fragmented, more resembling 
accumulations of courses and field experiences than careful movements through ideas and responsibilities.

We don't delude ourselves into thinking that it's possible to avoid such devolutions. However, for us, such inevitabilities only amplify the responsibility to attend to the coherence of any programmatic offering. To that end, we are conceiving of our teacher education program as a vibrant, learning system. In the model that we are exploring at the moment, topics of study are sequenced (roughly) and field experiences are structured as movements from discussions that are focused on the bodily, personal, interpersonal, social, institutional, cultural, and ecological issues - in essence, as an outward transversal of the learning systems illustrated in Figure 2. In terms of a 4semester (2-year) experience, we see this falling out as follows:

The first semester offers an overview through an introduction to contemporary discourses on learning and teaching. The intention is to surface, problematize, and explore alternatives to commonsense beliefs that often organize educational efforts within a rapidly changing world. Related field experience should engage pre-service teachers in inquiry of institutional learning settings through a block placement.

The second semester is focused on principles of individual learning and development. The intention is for participants to be introduced to theories and research that are focused on individual growth and the emergence of personal identity, ability, etc., and their relationships to the school curricula/specializations. Related field experience engages prospective teachers in inquiry of individual learning through a block placement (e.g., 4-week duration) in which they attend closely to the complexities of individual learning (i.e., no full-group instruction) by engaging with learners in various school contexts.

The third semester deals with principles of social and cultural engagement. The intention is for participants to be introduced to theories and research into collective, social, and cultural phenomena and their relationships to school curricula/specializations. Related field experiences should engage the prospective teachers in a block placement (e.g., 4-week duration) with a focus on collective engagement in which they work as a collaborative team (e.g., 2 or 3 candidates teaching in one classroom) with the classroom teacher to organize, implement, and interpret educational experiences.

The fourth and final semester of the initial teacher education experience is concerned with extending teaching and curriculum expertise. The intention is for participants to focus in more depth on their curriculum specializations or the core generalist curriculum areas. Related field experience should involve the prospective teachers in a block placement (e.g., 8-week duration) with a focus on individual teaching, working one-on-one to lead a class with a mentor teacher - in the context of a Partner Research School.

\section{Innovation 5: Partner Research Schools}

The practicum is a consistent and persistent 'problematic' of teacher education programs. It seems to be the site where all of the discontinuities, inconsistencies, and tensions of teacher education reveal themselves. The 'real world' of the classroom is pitted against the imaginings of the campus-based experiences, practice is pitted against theory, and so on. How might such superficial and unproductive tensions be avoided? That is, how might a field experience be framed so that teacher candidates are prompted to engage with the deep complexity of teaching, rather that to conceal it behind a veneer of simplistic binaries and technical proficiencies?

One possibility is to think of the context of the field experience as a deeply collaborative, research-rich setting in which university-based and school-based educators engage in ongoing shared work. We are in the process of exploring 
possibilities that might arise when a field experience site is not seen as a "host school" but as a Partner Research School in which faculty are seen as legitimate community members, engaged in intense collaborative specialist-based research.

We're still working out the details here, and we've already discovered that there is no one-size-fits-all (or even one-size-fits-most) model. However, to provide a sense of a workable structure that brings together all of the above innovations, one model that is currently under construction revolves around a master's cohort focused on the topic of teachers' disciplinary knowledge of mathematics. We expect that at least some of the participating teachers will be clustered in the same schools, and these schools might serve as research-and-field-experience hubs. Ideally, undergraduate and graduate students of education will be working together to understand and extend current developments in the research.

In other words, we are endeavoring to understand the structures and dynamics of many intersecting and overlapping systems complexly, invoking all of the images in Figure 1. The university and schools are not seen as separate entities, but as networked subsystems in a grander organization; teacher education and grade schooling are not seen as separate projects, but as aspects in a grander continuum of society's efforts to sustain and renew itself; teachers' disciplinary knowledge is not seen as a subset of researchers' disciplinary knowledge but as a coherently dynamic system that as much contributes to as draws from disciplinary domains.

\section{Closing Remarks}

We do not mean to suggest that somehow have it 'right' as we highlight game-changing ideas and describe some of the innovations these game-changers have prompted for us in teacher education. Rather, this discussion is motivated by the conviction that, while our theories and evidence will never be fully adequate to the task, we must nonetheless be attentive to the most current and best supported of available ideas.

Across the sort of teacher education initiatives we have described, a central goal is to dislodge public education from its rut of common sense - that is, unquestioned structures, uninterrogated practices, unnoticed simplifications. In addition to the programmatic emphases and structures noted above, another element in the project is take advantage of the powers of a well-networked collective. Our hope is to use emergent technologies and emergent insights into collective process to create structures that blur educational research and educational practice, campus-based and school-based components of teacher education, pre-service and in-service experiences, and so on. What, for example, might happen if pre-service candidates and practicing teachers were involved in complementary aspects of the same inquiries and taking courses developed around the same texts and topics? What might happen if teachers participated with researchers in restructuring the mathematical experiences of young learners? What might happen when differences in theoretical perspective are framed in terms of productive conversation rather than reductive argument?

Our guess is that such shifts in emphasis will help to move the cultural project of education to a new place, away from an ethos of segregated action and separated interests into a space of mutual challenge, joint interest, collective production. Importantly, the principal site of this cultural project is teacher education.

\section{References}

Bransford, J., Brown, A., \& Cocking, R. (Eds.). (2000). How people learn: brain, mind, experience, and school. Washington, DC: National Academy Press.

Chapman, O., Davis, B., Andrews, J., Friesen, S., Kawalilak, C., Lund, D., \& al. (2010, March 03). Bachelor of Education Task Force Report. Calgary, AB: Faculty of Education, University of Calgary.

Colvin, G. (2008) Talent is overrated: what really separates world-class performers from everybody else. New York: Portfolio. 
Crocker, R., \& Dibbon, D. (2008). Teacher education in Canada. Kelowna, BC: Society for the Advancement of Excellence in Education.

Davis, B., \& Sumara, D. (2006). Complexity and education: inquiries into learning, teaching, and research. New York: Routledge.

Davis, B., Sumara, D., \& Luce-Kapler, R. (2008). Engaging minds: changing teaching in complex times (2 ${ }^{\text {nd }}$ edn.). New York: Routledge.

Dweck, C. (2007). Mindset: the new psychology of success. New York: Ballantine.

Gambhir, M., Broad, K., Evans, M., \& Gaskell, J. (2008). Characterizing initial teacher education in Canada: Themes and issues. Toronto, ON: International Alliance of Learning Education Institutes.

Marton, F., \& Säljö, R. (1976). On qualitative differences in learning. British Journal of Educational Psychology, 46, 4-11.

Rivkin, S., Hanushek, E., \& Kain, J. (2005). Teachers, schools and academic achievement. Econometrica, $73(2), 417-458$

Shulman, L.S. (1986) Those who understand: knowledge growth in teaching. Educational Researcher, 15(2), 4-14.

\section{Acknowledgements}

This paper was originally presented at the $6^{\text {th }}$ Complexity Science and Educational Research Conference in Shanghai on November 7, 2010. We would like to thank Professor Zhang Hua of the East China Normal University for organizing the conference and for inviting us to present.

\section{About the Authors}

Brent Davis is Professor and Distinguished Research Chair in Mathematics Education at the University of Calgary. His research is developed around the educational relevance of developments in the cognitive and complexity sciences, and he teaches courses at the undergraduate and graduate levels in curriculum studies, mathematics education, and educational change. Davis has published the areas of mathematics learning and teaching, curriculum theory, teacher education, epistemology, and action research in journals that include Science, Harvard Educational Review, and Qualitative Studies in Education. His most recent book is Engaging Minds: Changing Teaching in Complex Times.

Dennis Sumara is Professor and Dean of the Faculty of Education at the University of Calgary. His research program focuses on the study of literary engagement and curriculum, analyses of normative and counter-normative discourses in teacher education, and the theoretical and practical implications of complexity science to the field of education. Sumara is author or coauthor of five books, including Why Reading Literature in School Still Matters: Interpretation, Imagination, Insight, which won the 2003 USA National Reading Conference's Ed Fry Book Award. He has published many research papers and essays in journals such as Harvard Educational Review, Educational Theory, Journal of Curriculum Studies, Journal of Literacy Research, and International Journal of Qualitative Research in Education.

(c) Copyright 2012. The authors, Brent Davis \& Dennis Sumara, assign to the University of Alberta and other educational and nonprofit institutions a non-exclusive license to use this document for personal use and in courses of instruction provided that the article is used in full and this copyright statement is reproduced. The authors also grant a non-exclusive license to the University of Alberta to publish this document in full on the World Wide Web, and for the document to be published on mirrors on the World Wide Web. Any other usage is prohibited without the express permission of the authors. 